Research Article

\title{
Students' perception of e-lectures from an undergraduate health sciences programme
}

\author{
Kerry Louise Hanna ${ }^{1}$ and Elizabeth Christina Lomas ${ }^{2}$ \\ ${ }^{1}$ Department of Orthoptics, University of Liverpool, United Kingdom (ORCID: 0000-0001-7357-7749) \\ ${ }^{2}$ Department of Orthoptics, University of Liverpool, United Kingdom (ORCID: 0000-0002-9096-6217)
}

\begin{abstract}
This research aims to explore undergraduate students' views on the inclusion of e-lectures within their clinical degree programme, and to identify the optimum usage for this increasingly popular teaching method. Considerable benefits of the flipped-classroom paradigm include increased student satisfaction, improved academic performance and opportunities to develop communication and team-building skills, providing rationale to integrate this approach into the Orthoptics programme. However, anecdotal observations of infrequently accessed e-lectures, alongside mixed student feedback, suggest that research is required to capture the views of the student cohort to inform the future use of e-lectures within the programme. A focus group was conducted in 2019, comprising 8 participants across the programme at the University of Liverpool in England. A topic guide supported a semi-structured discussion around the students' perceptions of e-lectures. Audio recordings underwent two counts of transcription, and thematic analysis was performed by the two authors. The core themes identified following thematic analysis of the transcript included the students' overall perceptions of e-lectures as a method of learning, and the perceived facilitators and barriers to utilising e-lectures. The key findings highlighted an unexpected perception that e-lectures are not valued as highly as face-to-face lectures. Consideration should be given to the aspects of e-learning that the student voice considered to be facilitators and barriers to engagement, as these appeared to contradict some of the well-established theories in published literature. The authors recommend that related programmes undertake similar scoping exercises to ensure that their students are gaining the maximum benefits from e-lectures.
\end{abstract}

Keywords: Flipped classroom; Students' perception; E-learning; Distance learning; Online; Health sciences

Article History: Submitted 5 May 2020; Revised 16 June 2020; Published online 22 June 2020

\section{Introduction}

Recently, the use of technology to facilitate teaching and learning in higher education (HE) has rapidly developed; it is now commonly incorporated as a key component in HE blended learning (Lage, Platt, \& Treglia, 2000). Recorded lectures (e-Lectures) are viewed at home in preparation for class activities where acquired knowledge is applied within the flipped-classroom blended learning approach (Prober \& Khan, 2013). Research suggests that such approaches that transcend traditional face-to-face lectures are most effective at engaging students and promoting learning (Ferreri \& O'Connor, 2013). Therefore, educators in HE are compelled to implement blended

\footnotetext{
Address of Corresponding Author

Dr. Kerry Louise Hanna, Department of Orthoptics, University of Liverpool, L69 3GB, England, UK.

$\square$ k.hanna2@liverpool.ac.uk
}

How to cite: Hanna, K. L. \& Lomas, E. C. (2020). Students' perception of e-lectures from an undergraduate health sciences programme. Journal of Pedagogical Research, 4(2), 125-138. 
learning as the complement of technologies available to enhance student learning rapidly grows and the expectations of the millennial generation in terms of technology in HE increases. It has been suggested that for this generation to engage academically, they require learning to be "reactionary and immediate"; hence the use of technology in HE is considered by some to be essential (O'Flaherty \& Phillips, 2015). This suggestion corresponds with previous literature on the theoretical backgrounds of e-learning, including the constructivism theory whereby students may be considered the "creators of their knowledge", with the incorporation of technology systems suggested as a key factor in delivering e-learning within this framework (Aparicio, Bacao, \& Oliveira, 2016; Bognar, 2016)

Including e-Lectures within a learner centered educational approach has been shown to increase student engagement and satisfaction, improve academic performance and provide opportunities to develop communication and team-building skills (Mason, Rutar Shuman, \& Cook, 2013; Wilson, 2013). Such skills and behaviours have particular relevance to a vocational health degree (such as Orthoptics) as graduates must engage in effective communication with patients and multi-disciplinary teams. Engagement is crucial to effective teaching and learning (Coates, 2006; Early, 2011), with suggestions that the most engaged students are able to reflect, evaluate and question ideas using inference to make connections (Hockings, Cooke, Yamashita, McGinty, \& Bowl, 2008). Qualitative research findings have suggested that flipped-classroom approaches incorporating e-Lectures enhanced engagement and learning experiences with opportunities to empower students (Forsey, Low, \& Glance, 2013; McLaughlin et al., 2013). Increased student satisfaction and improved student performance in diverse HE settings have been noted when electures are integrated within a flipped-classroom approach, compared to traditional teaching methods determined by various quantitative research methods. (Ferreri \& O'Connor, 2013; Mason et al., 2013; Missildine, Fountain, Summers, \& Gosselin, 2013; Prober \& Khan, 2013; Strayer, 2012).

However, some studies report negative student attitudes associated with blended teaching comprising e-Learning despite a co-existing improvement in academic performance (Ferreri \& O'Connor, 2013; McLaughlin et al., 2014; Strayer, 2012), due to reasons such as lack of motivation and class structure (Strayer, 2012), although these were minor in comparison to the additional positive aspects noted. However, these findings suggest variation in how this teaching method is interpreted amongst differing student cohorts. Such findings were further noted anecdotally through the low rate of students accessing e-lectures, alongside mixed verbal feedback within the Orthoptics programme at the University of Liverpool. E-lectures consisted of pre-recorded audio and visual lectures by internal and external teaching staff, with or without use of videos and images to support the written lecture materials, and with or without self-directed learning (SDL) embedded within the materials. In light of these anecdotal findings and conflicting evidence, research is required to capture the views of this specific student cohort to inform the future use of e-lectures within the programme.

Therefore, the aim of this qualitative research is to explore the students' views on the inclusion of e-lectures within their undergraduate degree programme, suggesting recommendations for optimum usage of this increasingly popular teaching method. A focus group was selected as the appropriate methodology to address this research question; a commonly used process to inform University policy and generate ideas for curriculum development through understanding of student experience (Breen, 2006). In order to recommend appropriate modifications to improve student learning, it was necessary to gain a rich understanding of the students' experiences in the context of the use of e-lectures (Murphy \& Yum, 1998).

It was posited that e-learning is viewed differently than contact teaching, and that views perhaps vary between the educators and recipient learners. From a review of the literature, it was surmised that both teaching methods possess merits and limitations, but it is important to note circumstances in which either should be used most effectively. Therefore, it was important to gauge students' perceptions of e-learning through their own experiences of using e-lectures within 
the University programme. Thus, qualitative exploration was employed using a subjectivist ontology, viewing reality as internal and unique to the participants (Marton, 1981).

\section{Method}

\subsection{Research Design}

Phenomenography was the chosen methodology for this research. Phenomenography is based on individuals' experiences and their relation with phenomena (in this case, e-learning) (Jackson, 2013; Marton, 1981; Trigwell \& Prosser, 2004), thus a qualitative method was required to explore the way in which student participants perceive e-lectures. The investigation is not directed at the phenomenon as such, but at the variation in students' ways of understanding the phenomenon (Larsson \& Holmström, 2007). Phenomenography aims for a collective analysis of individual experiences; thus, a focus group was chosen as the appropriate means of data collection.

\subsection{Participants}

It was apparent from anecdotal student feedback prior to undertaking this research that individuals had mixed opinions regarding e-lectures and viewpoints differed substantially between individuals. Hence an intention of the methodology was to promote exploration and clarification of views and to clarify dissimilarities through group interaction (Freeman, 2006; Kitzinger, 1995). Decisions not to segment academic years were made to encourage sharing and discussion of diverse views.

\subsection{Ethical Approval and Data Collection}

Institutional ethical approval was obtained from the University of Liverpool's Research Ethics Committee (reference 5168) and ethical considerations were adhered to throughout the research process. The student participants were recruited through advertisement, University intranet postings and word-of-mouth. A research topic guide, participant information sheet and consent were developed and approved institutionally. One semi-structured interview was planned based on the view that this research aimed to provide helpful insights into the current teaching methods and not to assist in major decision making (Krueger, 1994). Further, in depth research may be required in the future based on these findings, however the exploratory nature of this research is small scale, yet original and informative.

As recommended from previous studies (McNiff, Lomax, \& Whitehead, 1996), the student participants were fully informed of the voluntary nature of the research, and that it would in no way impact on their studies or academic qualifications. Prior to commencing the focus group discussion, the participant information sheets were read and time for questioning was allowed before signing consent for participation. The students were assured that anonymity will be fully maintained, and they were further reminded of the confidential nature of the research process and to respect other's opinions and experiences, which might be contradictory.

The topic guide was developed to direct the focus group discussion around six broad areas: the quantity of information delivered, the range of topics deemed suitable for e-lectures, the use of additional follow-up support, factors associated with a good and bad e-lecture, and the factors associated with student motivation in accessing e-lectures from home. In keeping with a phenomenographic design, he researchers utilised semi-structured open ended questions to facilitate discussion, and to allow the students to fully express their experiences and perceptions, such as "what do you think a high quality e-lecture comprises of, and why?" The focus group setting was in a local seminar room at the University for convenience to the students, with lunch provided before the focus group commenced to encourage initial, relaxed social interactions in the otherwise academic setting. 


\subsection{Data Analysis}

Audio recordings from the focus group underwent true/strict verbatim transcription (Universtiy Transcriptions, 2020) by both authors independently. The completed transcript was then read and re-read to allow the authors to fully immerse themselves in the students' narratives before undertaking the thematic analysis. Line-by-line, manual coding was employed by both authors to evaluate the transcripts and extract codes. Transcript-based analysis was followed, such that the transcript was read and coded by both authors independently to identify emerging themes and categorise codes (Braun \& Clarke, 2006; Krueger, 1994). Later, both authors met to discuss individual analyses and converging themes were established and agreed.

Both authors are clinical academics and underwent research practice training prior to conducting the work of this study. Both have prior qualitative research experience at postgraduate or postdoctoral level, and co-facilitated the focus group and later data analysis to ensure high quality research findings.

\subsection{Positionality and Epistemology}

The two authors are clinical Orthoptists and University lecturers on the undergraduate Orthoptics programme, with a background in clinical research. The University lecturers teaching on this programme noted poor engagement with e-learning materials by the student body, particularly with e-lectures. This led them to question the student cohort's perception of e-learning compared to contact teaching, and how this may impact on their higher education.

In order to avoid researcher bias, the researchers considered their positionality and previous conception of a lack of engagement with e-learning, and aimed to analyse the experiences of the students only. Qualitative research was chosen as the most appropriate means of collecting such views, prohibiting leading questions. This further eliminated the consideration of surveys in preference for a focus group discussion, as these might limit rich discussions through shared experiences (Ritter \& Sue, 2007).

\subsection{Recruited Participants}

One focus group (lasting 57 minutes) was held in May 2019; 8 participants, all female and registered within the Orthoptics undergraduate, Bachelor of Science degree programme (see Table 1). The participants were inclusive of all three years of the undergraduate programme, although variation in whether or not students paid for their tuition fees was discussed in the focus group. Therefore, this finding has been included in Table 1 and discussed later (see 3.4).

Table 1

The demographics of the recruited study participants

\begin{tabular}{llccc}
\hline Participant (P) number & Gender & $\begin{array}{c}\text { Age (at time of } \\
\text { research) }\end{array}$ & $\begin{array}{c}\text { Year of study (at time } \\
\text { of research) }\end{array}$ & $\begin{array}{c}\text { Paid vs funded } \\
\text { tuition fees }\end{array}$ \\
\hline P1 & Female & 18 & 1 & Student paid \\
P2 & Female & 20 & 2 & Student paid \\
P3 & Female & 20 & 2 & Student paid \\
P4 & Female & 21 & 3 & NHS funded \\
P5 & Female & 21 & 3 & NHS funded \\
P6 & Female & 21 & 3 & NHS funded \\
P7 & Female & 21 & 3 & NHS funded \\
P8 & Female & 21 & 3 & NHS funded \\
\hline
\end{tabular}

\section{Results}

Three central themes emerged from the transcripts as shown in the coding tree (see Table 2). These themes are framed in terms of the students' overall expectations relating to e-learning, and their perceived facilitators and barriers in utilising e-lectures. Each theme is discussed separately below in relation to the student body's perceptions of this phenomenon (e-learning). Of note, the students were encouraged to fully describe their reasoning behind their perceptions of e-lectures and this 
often led to suggested recommendations to improve this method of teaching. Although findings from qualitative research should not be generalised to a wider population (Krueger, 1994), the suggestions made by the students were deemed important to include in the discussion, as these recommendations may resonate with readers and encourage similar considerations of e-learning to be deliberated in other institutions.

Table 2

The coding tree developed from the thematic analysis of the focus group transcript

\begin{tabular}{ll}
\hline Theme & Codes \\
\hline Student expectations & - The students' perceptions and expectations of HE generally \\
relating to e-learning & - The students' expectations from the undergraduate \\
& - The notion of "spoon-feeding" and the desire to be actively \\
& - The desire to be told what they "need to know" \\
& - The belief that the responsibility for the students' learning \\
& - rests with the educators \\
\hline Perceived facilitators to & - Increased motivation to learn \\
utilising e-lectures & - Suitable topics \\
& - The structure of the e-lecture \\
\hline Perceived barriers to & - Low perception of "value for money" \\
utilising e-lectures & - Technical issues \\
& - Toss of peer learning opportunities \\
\hline
\end{tabular}

\subsection{Students' Expectations related to e-learning}

The students' perceptions of e-lectures consistently coalesced with their perceptions and expectations of HE generally. A theme that was frequently raised was the desire to only learn content that was relevant to their learning outcomes, particularly in terms of assessment. This quote from P8 demonstrates that, at times, the students perceived e-lectures to be unclear in ascertaining which information was necessary for them to learn.

P8 "I was just thinking I don't know what I need to know from this (e-)lecture... you just feel a bit lost. You just feel... how much of this am I supposed to learn?"

However, during the focus group, the students did acknowledge that this expectation may not be appropriate in a HE institution, although despite this acknowledgement, this concept of "what I need to know" was subsequently and frequently discussed. P3's extract below exemplifies this theory, suggesting that clearly distinguishing between essential and surplus information was important to the group.

P3: "I like to have that border there between what we need to know, and what is supplementary to what we need to know"

The students' desire to be informed of the clear relevance of the teaching material, denotes a need to prioritise topics of learning when presented with an overwhelming amount of information. Where the educator had clearly stated in the e-lecture what information was necessary to learn for assessments, and what was typically surplus to enhance their understanding, this was viewed as a positive aspect that encouraged the students' engagement with the e-lecture. P1's statement below 
describes a lack of motivation to undertake the e-learning without clear relevance to their core learning outcomes.

P1: "...we just need to know...how this is going to involve [us]...otherwise people don't see the relevance of it and then won't do it [engage with the e-lecture]. We need to think, what has this got to do with what I have got to do?"

Conversely, this aspect of the discussion may have simply implied a desire of the students to be "spoon-fed" information (Dehler \& Welsh, 2013) in order to support their subsequent University examinations. This was directly mentioned by the participants, as shown in P1's comment below and the ensuing discussion where the students used humour to confess that they would like to be spoon-fed information, despite acknowledging the unrealistic expectations of this. Therefore, educators should be cautious in sharing such information, as a true understanding of the material may be sacrificed to support quick revision.

\section{P1: "I feel like, you just need to be told, "so, this is what you are going to be tested on"." \\ P4: “...it's hard because [at] University, you're not meant to be spoon-fed, so it is difficult [unfinished]" \\ P5: "whereas, we're like "please spoon feed us" ha ha ha"}

Furthermore, the participants discussed the notion that the responsibility for learning was transferred to the students when using e-learning materials, as opposed to the educators, which ultimately reduced the students' perception that they were "being taught". Instead, they spoke of e-lectures as revision tools to supplement their learning, but these were not necessarily seen as mandatory lectures. The prose below from P5 portrays the view that the students consider electures to be a resource, rather than a learning experience, and further implies dissatisfaction at the concept of students being expected to undertake SDL.

P5 "I think the thing about e-lectures is that you're basically... self-taught, so, "here is a resource, now teach it to yourself""

Furthermore, the quote below from P1 promotes the suggestion that the students did not perceive watching e-lectures to be an effective learning technique, with an inference that this approach was too passive. Suggestions made by the participants in terms of augmenting e-lectures with active learning tasks to increase engagement (discussed later in 3.3) supports this notion that the participants did not believe that they were actively learning by watching e-lectures alone.

P1: "the thing is with e-lectures, you don't feel you're being taught, like you just feel like you are watching something and making a few notes, but it doesn't feel like learning"

\subsection{Perceived Facilitators to Utilising e-lectures}

The second theme that emerged from the focus group transcript centred on the aspects of the electures that facilitated learning. There was a general consensus amongst the students that electures allowed for flexible working and provided the students with the opportunity to undertake their learning at a time that best suited them, or when they felt most motivated. The extract below from P5 exemplifies this suggestion that the flexible and accommodating aspect of e-learning can enhance information retention.

P5: "I like e-lectures... you can make sure that you are in the right frame of mind, because when you come in to Uni [for a face-to-face lecture], maybe you are really tired and you don't really want to be there, whereas, if you are going to turn an e-lecture on, then you are going to be in the mood to actually take in the information and then you are more likely to get the best out of it..." 
One perceived facilitator in utilising e-lectures included the educator delivering the materials, with a strong preference for e-lectures to be delivered by internal teaching staff, as opposed to external or guest lecturers. A large component of the discussions focused on the lack of social or personal interaction with e-lectures (discussed later in 3.4), which was heightened in instances where the external lecturer was unfamiliar to the student. As a result, the students reported discomfort in emailing the lecturer for further information or clarification of the content delivered within the e-lecture. If the students feel uncomfortable contacting the lecturer, then optimum learning cannot be achieved through this method of teaching.

P8: "...sometimes it is easier because we have met [the external lecturer], so then I know what he is like... it is weird if you are just listening to someone's voice and you can't put a name to a face. Even if [the external lecturer] did one lecture with us [face-to-face] and the rest on e-lectures [unfinished]"

Therefore, e-lectures delivered by internal staff were preferred by the student cohort, although it was acknowledged that this may not always be feasible. One possible solution offered by P8 in the above prose, suggests that the external lecturer delivers the first lecture face-to-face, to allow for a personal introduction and to gain some familiarity, whilst subsequent lectures could be delivered as e-learning thereafter.

Finally, it was discussed that the structure and content of the e-lectures influenced the compliance and motivation of the students in undertaking the e-learning materials. Where the students felt that complex topics that required critical thinking, as described below by P5 as "investigating and managing clinical conditions", then the students suggested contact teaching best supported this learning. The opportunities to ask questions during contact teaching was the suggested reason behind this assertion, and is discussed further in 3.4. Conversely, standalone topics which appeared to support the core learning outcomes were deemed to be a more appropriate e-lecture topic, as less discussion is required in the teaching session to consolidate their understanding.

P5: "It [suitability of e-lectures] is more [pertinent to] what topics would be suitable or appropriate, because I think the topics that are more like, "oh, you've got to really think about it", like the modules where we are diagnosing and investigating and managing [clinical conditions], like those kinds of [lectures] really benefit from face-to-face [teaching]. But the ones that are just facts that you need to learn, they can be... beneficial as an e-lecture. So, it just depends on the topic."

Therefore, the students concurred that e-learning was less suitable when teaching in depth or new topics for the first time, without an initial face-to-face lecture to introduce the topic, which compares to the aforesaid discussion regarding familiarity with the teacher. In addition to the topics taught, the students contested the length of the e-lectures. The discussion below between P4 and P1 explores the preferred length of time that an e-lecture should adhere to, with the students reporting a loss of interest and attention if the e-lecture exceeded 20 minutes.

P4: "with the 20 minute [e-lectures], you can be like, "ok, I have 20 minutes so I can do it and then take a break and do another one", because I wouldn't want to just pause a lecture halfway through and come back to it... it is a bit hard"

P1: "[e-lectures] can be like 45 minutes... flipping heck! You open the power point slides and go, "how many slides?" We have had ones with over 150 slides, and people just open them and go, "no" - close it again, not a chance I am doing that."

Furthermore, e-lectures with an interactive component, such as images, videos, workbooks and quizzes were highlighted as positive factors that encouraged motivation to utilise the e-lecture and facilitated learning. In response to P1's remark that that an e-lecture "doesn't feel like learning", P8 postulated that a more interactive component to the teaching session could tackle this issue and enhance the quality of the e-lecture. 
P8: "...there has to be interaction... maybe a little quiz at the end [of the e-lecture]... that would be nice. Or like a worksheet to go with the lecture, so it's like, "while you watch the lecture, do this worksheet""

\subsection{Perceived Barriers to Utilising e-lectures}

The final theme that emerged from the focus group discussion encompassed the individual barriers to undertaking e-learning, as experienced by the student participants. These barriers included physical entities that prevented them from accessing the e-learning materials, as well as the psychological or emotive barriers due to the loss of social interactions and peer support. The quote below from P1 portrays technical issues with e-learning as a physical barrier to engaging with this teaching method, which adds to earlier discussion around the preferred topics and length of e-lectures.

P1: "I always have to have the volume turned up... and I was saying to everyone in my flat "right, you need to be quiet, I can't hear this at all". It's on full volume and it's like she's [lecturer] whispering. I don't know if it is just the recording... but it is really quiet."

The focus group discussion often returned to the expense of HE, which appeared to inflate students' expectations of the programme to some extent, resulting in a notion that e-learning was not mandatory, or that they had more control of where and when they could undertake their own learning. What's more, P1's account below depicts a sense of higher social status attached to contact lectures at University, when comparing e-learning to the "Open University", which consists primarily of online teaching courses, as opposed to monitored attendance and contact teaching at competitive HE institutions. Ultimately, the high expense of their University fees appeared to contribute to this perceived image of higher status, and the students expressed a desire to undertake learning in the form that protects this image. This notion of image preservation draws on sociologist Irving Goffman's theory of presentation of self (Goffman, 1959).

P1: "We are paying a lot of money... but...essentially, it is like being at an open University if it is just all online... you have paid a lot of money to move out when you could have just...not bothered."

Furthermore, P1's excerpt expresses an expectation of having "value for money" at University. This is likely to be due to inflated tuition fees in the UK, alongside the loss of the National Health Service (NHS) bursaries for clinical degree courses, which was experienced by a number of the group participants (Hubble, Foster ., \& P., 2017). This expectation further highlights a requirement for e-learning to be seen to be as important and relevant to their core teaching materials as contact teaching, otherwise engagement will probably be low.

The quote below shows P8 making a direct comparison between fee-paying and non-fee-paying students (as seen in Table 1). This comparison portrays key differences in perception and expectations of $\mathrm{HE}$ as a result of this expense. P8 suggests where students pay their own tuition fees, it could be assumed that they would have a greater motivation to comply with teaching materials to avoid "wasting" money on a failed degree course. However, her excerpt states that greater engagement with the clinical teaching on the programme was experienced when the NHS paid for the students' tuition fees due to fear of being reprimanded, implying that their degree was "gifted" by an external company that could revoke the offer if attendance and compliance were low. Therefore, engagement with e-learning was reportedly greater with this group of funded students.

P8: "it's not the same for you guys [self-paying fees]... we was like (sic) the NHS are paying for your course, like, "you need to go, we [NHS] are paying to watch your attendance. Unless you have this, you won't pass". So, I was petrified [pause] surely it is more of an incentive to go if you are paying. You are paying nine grand... so, you can only blame yourself if you don't do it [e-learning]." 
A further, prominent topic that developed naturally in the focus group discussion, and that has been touched on briefly in 3.3, concentrated on the social aspect of HE, which was deliberated not only as important to the students' learning, but to their overall enjoyment on their University programme. P8 below suggests that a balanced ratio of contact and e-lectures should be exercised to ensure that students do not lose the social enjoyment of coming to University, which ultimately leads to increased engagement in the programme.

P8: "if you had an equal ratio then it's good because... sometimes you just want to sit at home and do a bit of work, but then if you come into uni, it gets you motivated. You're coming in to see your mates. I don't think I could ever have it as just a lot of e-lectures"

The comment below from P3 describes the concept that learning a health sciences undergraduate course requires a certain level of social interaction (described below as social "things") to develop the communication skills necessary to become a practicing clinician. Therefore, despite the aforementioned positive aspects to utilising e-lectures, the loss of such social interactions with e-learning could potentially impact the overall quality of the clinical skills that the student develops from the course.

P3: "it is like the whole of our degree is based around the social "things", talking to people and dealing with people and assessing people. So having e-lectures where there is no face to a name, it is a bit dissociative"

Furthermore, the addition of peer support in higher learning is lost when e-lectures are used in lieu of contact teaching sessions. Although HE supports an ethos of independent learning, this was a common complaint of the student group. P1's account below described the "isolation" of independent e-learning and the contrasting benefits of group discussions for consolidating understanding of contact lecture content.

P1: "In a (face-to-face) lecture, someone will ask a question and you think "oh, I wouldn't have thought of that"...whereas, you are quite isolated with an e-lecture, just sitting there doing it by yourself [pause]. If you are the first person to do it [e-lecture], and you message people, "has anyone done it yet", and they are like, "no"... you can end up being the only one who has done it... and then they're asking the questions and you're like "well, I don't know either""

Likewise, the student participants reported that the use of facial expressions, humour and hand gestures are important in face-to-face teaching to describe context of the topic, and to enhance student engagement. These cues were reportedly lost with e-learning, as shown in P3's "impersonal" account of e-lectures and P1's earlier description that e-lectures do not feel like learning (see 3.2). The students agreed that this lack of social interaction impacted on the quality of the teaching and learning.

P8: "I feel like you pay more attention if [teaching] is face-to-face..."

P3: "...especially with new content, I think it is important to have [teaching] face-to-face, e-lectures just takes the personality out of it... I have no idea who this person is"

In addition to the aforesaid preferences regarding teaching staff, suitable topics, and interactive components of e-lectures as described in 3.3, the students reported that the lack of attendance monitoring with e-lectures, compared to that which is required in face-to-face lectures, lowered the student's perceived importance of the e-learning materials. For this reason, it was reported that limited compliance and attention is given by the students to e-learning materials. P5, below, postulated that incorporating a method of attendance monitoring to the e-lecture, as well as issuing reminders to the students prompting them to access the e-lectures, would ensure compliance by the student, and ultimately the acquisition of knowledge from the materials. 
P5: "...it's all about enhancing the importance of e-lectures... It's an e-lecture, "it isn't important" but if you have to attend or tick to say you've done it... then that shows [the student] "oh, I need to be doing this"'"

\section{Discussion}

The findings from this research successfully explored the Orthoptic students' experiences of using e-lectures, which centred around three core themes: their expectations relating to e-learning, and their perceived facilitators and barriers to engaging with this teaching method. The use of eLectures incorporated into a flipped-classroom blended learning approach has widely shown to be effective in improving academic performance and satisfaction (Mason et al., 2013; Strayer, 2012; Wilson, 2013; Yeung, 2014). Moreover, it is suggested that technology is essential when educating the millennial generation (O'Flaherty \& Phillips, 2015). However, the general findings from this research suggest that technology in the context of e-lectures was considered, by the students, to be subsidiary to traditional face-to-face learning.

It was observed that the Orthoptic student cohort did not always engage with the e-lectures, and in fact, many of the themes discussed during this focus group represent dissatisfaction. A systematic review exploring of the use of e-learning with health professional students reported barriers to using of this method effectively, which included factors such as students' resistance to change, associated costs, inadequate technology, lack of skills, and need for a component of faceto- face teaching (Childs, Blenkinsopp, Hall, \& Walton, 2005). Although cost was not an issue with the free university materials accessed by the student cohort of this study, findings did reflect similar barriers within technical issues of e-lectures, a lack of motivation and a desire for face-toface follow-up teaching.

Furthermore, the findings concur with earlier suggestions that lack of motivation and class structure result in negative student attitudes (Strayer, 2012), however the student participants from this research further offered physical and sociological limitations as possible reasons for this lack of engagement with e-learning. Although the factors contributing dissatisfaction in relation to electures are likely to be multifactorial, many of them can be associated with an overarching sense of unrealistic expectations of HE (Long, Tricker, Rangecroft, \& Gilroy, 1999; Parasuraman, Zeithaml, \& Berry, 1985). Therefore, this research lays emphasis on the importance of effectively enlightening current and prospective students of the expectations of HE, to avoid related dissatisfaction and disengagement with e-learning.

In part, inappropriate expectations appeared to be associated with a perception that e-learning does not represent "value for money" and resulted in a general desire to be "spoon-fed" "need-toknow" information (Dehler \& Welsh, 2013). As the price of HE rises in the UK, students are increasingly viewed as consumers, aware of their "customer rights" and demanding value for money (Darlaston-Jones et al., 2003). It has become more appropriate to discuss HE in the context of the "service gap", developed in the business sector to assess customer satisfaction against customer expectations; the concept being that when expectations are not met, disappointment results, regardless of the quality of service (Long et al., 1999; Parasuraman et al., 1985). It is acknowledged that students arrive at University with differing expectations of what constitutes quality education and varying levels of preparedness for University life and study due to inadequate information and naivety (Cheong Cheng \& Ming Tam, 1997; McInnis, Hartley, Polesel, \& Teese, 2000). It is widely published that there is a lack of awareness among undergraduates of the necessity to undertake independent learning in HE, which is relevant to consider as the students in this research perceived e-lectures to be a self-directed task. The themes discussed from this focus group coincide with the findings of the studies cited above, and represent that the participants have unrealistic expectations relating to HE.

In addition, a related finding identified through this research was the apparent unwillingness by the students to take responsibility for learning, when the responsibility was shifted from educator to student during flipped-classroom teaching. This finding has also been examined in 
previous literature with varied conclusions. Some authors have reported that students perceive academic success or failure to be linked with persistence and self-motivation (Killen, 1994; Schmelzer, Schmelzer, Figler, \& Brozo, 1987), whilst others do not relate their own behaviour to their performance (Devlin, 2002). These findings reaffirm a key recommendation from this research, whereby HE institutions must seek to manage student expectations, particularly in the context of using technology and independent learning.

Similar qualitative studies found that the flipped-classroom approach allowed students to develop communication and team building skills (Ishak, Kurniawan, Zainuddin, \& Keumala, 2020; Mason et al., 2013; Wilson, 2013). However researchers have acknowledged that the voluntary nature of qualitative data collection will not capture all student views, recognising that there are potential students who have not experienced such benefits from e-lectures (Ishak et al., 2020). Negative views were found in the current qualitative study of orthoptic students, where themes of isolation and lack of socialisation were described. Furthermore, interactions with peer learners have been shown to strongly contribute to student satisfaction (Goh, Leong, Kasmin, Hii, \& Tan, 2017), and the participants specifically noted this loss of peer support when undertaking elearning. Concurrently, when asked "what really mattered to them" students at another UK University highly valued being supported by peer learning groups (Money et al., 2017). Collectively, these findings highlight the significance of incorporating peer learning opportunities within the flipped learning approach, where possible, for it to be used effectively.

Contrary to research indicating that e-learning within the flipped-classroom paradigm is shown to promote student engagement (Critz \& Knight, 2013; Forsey et al., 2013; McLaughlin et al., 2013), the student participants inferred that they were, in general, disengaged with the e-lectures; categorising them as low priority. Notably, the students felt less engaged when guest lecturers delivered the e-lectures and posited that new topics are delivered face-to-face by internal lecturers. This finding supports earlier research that suggests the theoretical context of topics is first explained and discussed in contact lectures, before involving guest lecturers to reinforce learned material (Albrecht, 2012; Li \& Guo, 2015). Furthermore, the students described aspects of face-toface teaching that they considered engaging, such as humour, facial expressions, and educator familiarity, which are frequently lost in e-lectures. This insight allows for future adaptations of electure delivery to be considered, possibly using a video component, to ensure they are as engaging as possible.

Perceived facilitators to engaging with e-lectures, as reported from this research, included the addition of accompanying active learning tasks, such as quizzes, workbooks and attendance monitoring, implying the students do not feel they have sufficient opportunities to apply or consolidate topics addressed in e-learning. This suggestion of additional learning activities is supported by previous research, which identified that active learning activities promote higherorder thinking processes to help students develop rich and complex knowledge structures (Grabinger \& Dunlap, 1995). A comparative, quasi-experimental study concluded that activelearning tasks enhance student learning in both flipped and non-flipped classroom approaches to teaching (Jensen, Kummer, \& Godoy, 2015). However, little evidence exists which specifically evaluates the impact of incorporating each of the available learning tasks alongside e-lectures in the flipped-classroom approach, suggesting an area for future research enquiry. In addition, shorter lectures of $\leq 20$ minutes, and carefully selecting the topics most suitable for e-lecture delivery were amongst the suggested recommendations from the student cohort to encourage engagement and effective learning. Such amendments to e-lectures could further address the abovementioned issues with lack of engagement. If all the elements of the flipped-classroom paradigm are not combined, such that e-lectures are successfully blended with knowledge application opportunities, then the expected benefits will not be ascertained. 


\section{Conclusions}

Overall, the key findings from this small-scale, qualitative exploration of e-lectures in the clinical Orthoptics HE programme, highlighted an unexpected perception that e-lectures are not valued as highly as face-to-face lectures. It is an obligation of the University staff to ensure that this perception is altered if this teaching method is to be as effective as stated in previous literature. This research has produced several suggestions in order to address this altered perception. These include the use of accompanying active learning materials, shorter lecture lengths of $\leq 20$ minutes, identifying and addressing any known technical issues when recording the e-lectures, and to enhance communication between lecturers and students to raise full awareness of the University's expectations of the students in terms of independent learning.

Consideration should be given to the aspects of e-learning that the student voice considered to be facilitators and barriers to engagement, as these appeared to contradict some of the wellestablished theories in published literature. However, these opposing views may be specific to students enrolled in healthcare courses and not representative of a majority student body. It should be reiterated that these findings are small-scale, and qualitative research is not to be generalised to a wider student population. Nevertheless, the findings highlight issues with elearning that have not been widely publicised previously and thus, should be considered by similar programmes using this teaching method on their University courses. The authors recommended that such programmes undertake similar scoping exercises to ensure that their students are gaining the maximum benefits from e-lectures.

\section{Declaration of interest}

The authors have no competing interests to declare.

\section{Acknowledgement}

The paper has joint first authors, as both authors contributed equally to the paper.

\section{References}

Albrecht, J. N. (2012). Authentic learning and communities of practice in tourism higher education. Journal of Teaching in Travel and Tourism, 12(3), 260-276. doi:https:/ / doi.org/10.1080/15313220.2012.704254

Aparicio, M., Bacao, F., \& Oliveira, T. (2016). An e-learning theoretical framework. Journal of Educational Technology \& Society, 19(1), 292-307.

Bognar, B. (2016). Theoretical backgrounds of e-learning. Croatian Journal of Education, 18(1), 225-256. doi:https://doi.org/10.15516/cje.v18i1.1475

Braun, V., \& Clarke, V. (2006). Using thematic analysis in psychology. Qualitative Research in Psychology, 3(2), 77-101.

Breen, R. L. (2006). A practical guide to focus-group research. Journal of Geography in Higher Education, 30(3), 463-475. doi:https:// doi.org/10.1080/03098260600927575

Cheong Cheng, Y., \& Ming Tam, W. (1997). Multi-Models of Quality in Education. Quality assurance in Education, 5(1), 22-31. doi:https:// doi.org/10.1108/09684889710156558

Childs, S., Blenkinsopp, E., Hall, A., \& Walton, G. (2005). Effective e-learning for health professionals and students-barriers and their solutions. A systematic review of the literature-findings from the HeXL project. Health Information \& Libraries Journal, 22(s2), 20-32. doi:10.1111/j.1470-3327.2005.00614.x

Coates, H. (2006). Student Engagement in Campus-based and Online Education. Oxon:

Critz, C. M., \& Knight, D. (2013). Using the flipped classroom in graduate nursing education. Nurse Educator, 38(5), 210-213. doi:10.1097/NNE.0b013e3182a0e56a

Darlaston-Jones, D., Pike, L., Cohen, L., Young, A., Haunold, S., \& Drew, N. (2003). Are they being served? Student expectations of higher education. Research Online, 13(1), 31-52.

Dehler, G. E., \& Welsh, M. A. (2013). Against spoon-feeding. for learning. reflections on students' claims to knowledge. Journal of Management Education, 38(6), 875-893. doi:10.1177/1052562913511436 
Devlin, M. (2002). Taking responsibility for learning isn't everything: A case for developing tertiary students' conceptions of learning. Teaching in Higher Education, 7(2), 125-138.

Early, S. L. (Ed.) (2011). Book Review: Student Engagement Techniques: A Handbook for College Faculty.

Ferreri, S. P., \& O'Connor, S. K. (2013). Redesign of a large lecture course into a small-group learning course. American journal of pharmaceutical education, 77(1), 13-13. doi:10.5688/ajpe77113

Forsey, M., Low, M., \& Glance, D. (2013). Flipping The Sociology Classroom: Towards A Practice Of Online Pedagogy. Journal of Sociology, 49(4), 471-485. doi:https:/ / doi.org/10.1177\%2F1440783313504059

Freeman, M. (2006). Nurturing dialogic hermeneutics and the deliberative capacities of communities in focus groups. Qualitative Inquiry, 12(1), 81-95. doi:10.1177/1077800405282797

Goffman, E. (1959). The Presentation of Self in Everyday Life. Middlesex: Pelican Books.

Goh, C., Leong, C., Kasmin, K., Hii, P., \& Tan, O. (2017). Students' experiences, learning outcomes and satisfaction in e-learning. Journal of E-learning and Knowledge Society, 13(2), 117-128. doi:https:// www.learntechlib.org/p/188116/

Grabinger, R. S., \& Dunlap, J. C. (1995). Rich environments for active learning: A definition. ALT-J, 3(2), 5-34. doi:https:// doi.org/10.1080/0968776950030202

Hockings, C., Cooke, S., Yamashita, H., McGinty, S., \& Bowl, M. (2008). Switched Off? A Study Of Disengagement Among Computing Students At Two Universities. Research Papers in Education, 23(2), 191201. doi:https:// doi.org/10.1080/02671520802048729

Hubble, S., Foster ., \& P., B. (2017). Reform of support for healthcare students in England. London: https:// dera.ioe.ac.uk/28823/1/CBP-7436.pdf

Ishak, T., Kurniawan, R., Zainuddin, Z., \& Keumala, C. M. (2020). The role of pre-class asynchronous online video lectures in flipped-class instruction: Identifying students' perceived need satisfaction. Journal of Pedagogical Research, 4(1), 1-11. doi:https://doi.org/10.33902/jpr.v4i1.145

Jackson, E. (2013). Choosing a methodology: Philosophical underpinning. Practitioner Research in Higher Education, 7(1), 49-62. doi:https:/ /ojs.cumbria.ac.uk/index.php/prhe

Jensen, J. L., Kummer, T. A., \& Godoy, P. (2015). Improvements from a flipped classroom may simply be the fruits of active learning. CBE - Life Sciences Education, 14(1), ar5,1-12. doi:10.1187/cbe.14-08-0129

Killen, R. (1994). Differences between students' and lecturers' perceptions of factors influencing students' academic success at university. Higher Education Research and Development, 13(2), 199-211. doi:https://doi.org/10.1080/0729436940130210

Kitzinger, J. (1995). Qualitative research. Introducing focus groups. the British Medical Journal, 311(7000), 299302. doi:https://doi.org/10.1136/bmj.311.7000.299

Krueger, R. A. (1994). Focus Groups (Second ed.). California: Thousand Oaks.

Lage, M. J., Platt, G. J., \& Treglia, M. (2000). Inverting the classroom: a gateway to creating an inclusive learning environment. The Journal of Economic Education, 31(1), 30-43.

Larsson, J., \& Holmström, I. (2007). Phenomenographic or phenomenological analysis: does it matter? Examples from a study on anaesthesiologists' work. International Journal of Qualitative Studies on Health and Well-being, 2(1), 55-64. doi:https://doi.org/10.1080/17482620601068105

Li, L., \& Guo, R. (2015). A student-centered guest lecturing: A constructivism approach to promote student engagement. Journal of instructional pedagogies, 15, 1-7.

Long, P., Tricker, T., Rangecroft, M., \& Gilroy, P. (1999). Measuring the Satisfaction Gap: Education in the Market-Place. Total quality management, 10(4-5), 772-778. doi:https://doi.org/10.1080/0954412997794

Marton, F. (1981). Phenomenography - describing conceptions of the world around us. Instructional science, 10(2), 177-200. doi:https://doi.org/10.1007/BF00132516

Mason, G., Rutar Shuman, T., \& Cook, K. E. (2013, June). Inverting (Flipping) Classrooms - Advantages and Challenges. Paper presented at the ASEE Annual Conference and Exposition, Conference Proceedings, Atlanta, Georgia.

McInnis, C., Hartley, R., Polesel, J., \& Teese, R. (2000). Non-completion in vocational education and training and higher education. Melbourne: The University of Melbourne.

McLaughlin, J. E., Griffin, L. M., Esserman, D. A., Davidson, C. A., Glatt, D. M., Roth, M. T., ... Mumper, R. J. (2013). Pharmacy student engagement, performance, and perception in a flipped satellite classroom. American Journal of Pharmaceutical Education, 77(9), 196-196. doi:10.5688/ajpe779196

McLaughlin, J. E., Roth, M. T., Glatt, D. M., Gharkholonarehe, N., Davidson, C. A., Griffin, L. M., . . . Mumper, R. J. (2014). The flipped classroom: a course redesign to foster learning and engagement in a health professions school. Academic Medicine, 89(2), 236-243. doi:10.1097/ACM.0000000000000086

McNiff, J., Lomax, P., \& Whitehead, J. (1996). You and your action research project. London: Routledge. 
Missildine, K., Fountain, R., Summers, L., \& Gosselin, K. (2013). Flipping the classroom to improve student performance and satisfaction. Journal of Nursing Education, 52(10), 597-599. doi:https://doi.org/10.3928/01484834-20130919-03

Money, J., Nixon, S., Tracy, F., Hennessy, C., Ball, E., \& Dinning, T. (2017). Undergraduate student expectations of university in the United Kingdom: What really matters to them? Cogent Education, 4(1), 1301855. doi:https:// doi.org/10.1080/2331186X.2017.1301855

Murphy, D., \& Yum, J. C. (1998). Understanding Hong Kong distance learners. Distance Education, 19(1), 6480. doi:https:// doi.org/10.1080/0158791980190106

O'Flaherty, J., \& Phillips, C. (2015). The use of flipped classrooms in higher education: a scoping review. The Internet and Higher Education, 25, 85-95. doi:https://doi.org/10.1016/j.iheduc.2015.02.002

Parasuraman, A., Zeithaml, V. A., \& Berry, L. L. (1985). A conceptual model of service quality and its implications for future research. Journal of Marketing, 49(4), 41-50. doi:10.1177/002224298504900403

Prober, C. G., \& Khan, S. (2013). Medical education reimagined: a call to action. Academic Medicine, 88(10), 1407-1410. doi:doi: 10.1097/ACM.0b013e3182a368bd

Ritter, L. A., \& Sue, V. M. (2007). Introduction to using online surveys. New Directions for Evaluation, 2007(115), 5-14. doi:https://doi.org/10.1002/ev.230

Schmelzer, R. V., Schmelzer, C. D., Figler, R. A., \& Brozo, W. G. (1987). Using the critical incident technique to determine reasons for success and failure of university students. Journal of College Student Personnel, 23(3), 261-266.

Strayer, J. F. (2012). How learning in an inverted classroom influences cooperation, innovation and task orientation. Learning Environments Research, 15(2), 171-193. doi:10.1007/s10984-012-9108-4

Trigwell, K., \& Prosser, M. (2004). Development and use of the approaches to teaching inventory. Educational Psychology Review, 16(4), 409-424. doi:https:/ / doi.org/10.1007/s10648-004-0007-9

Universtiy Transcriptions. (2020). True verbatim transcript. Retrieved from https://www.universitytranscriptions.co.uk/true-verbatim-transcript/

Wilson, S. G. (2013). The flipped class: a method to address the challenges of an undergraduate statistics course. Teaching of Psychology, 40(3), 193-199. doi:10.1177/0098628313487461

Yeung, K. (2014). Making 'the flip'work: barriers to and implementation strategies for introducing flipped teaching methods into traditional higher education courses. New Directions in the Teaching of Physical Sciences, 1(10), 59-63. doi:https:// doi.org/10.29311/ndtps.v0i10.518 